\title{
REFLECTION
}

\section{Caring for Rohingya Refugees With Diphtheria and Measles: On the Ethics of Humanity}

\author{
Ramin Asgary, $M D^{1-3}$ \\ 'Doctors Without Borders, Paris, France \\ ${ }^{2}$ Milken Institute School of Public Health, \\ George Washington University, Wash- \\ ington, DC
}

${ }^{3}$ Weill Cornell Medical College, New York, New York

\section{$m_{i}$ MORE ONLINE www.annfammed.org}

Conflicts of interest: author reports none.

\section{CORRESPONDING AUTHOR}

Ramin Asgary, MD Weill Cornell Medical College 525 East $68^{\text {th }}$ Street, F 2008

New York, NY 10065 ga263@columbia.edu

\begin{abstract}
Hundreds of thousands of Rohingya refugees arrived in Bangladesh within weeks in fall 2017, quickly forming large settlements without any basic support. Humanitarian first responders provided basic necessities including food, shelter, water, sanitation, and health care. However, the challenge before them-a vast camp ravaged by diphtheria and measles superimposed on a myriad of common pathologies-was disproportionate to the resources. The needs were endless, resources finite, inadequacies abundant, and premature death inevitable. While such confines force unimaginable choices in resource allocation, they do not define the humanitarian purpose-to alleviate suffering and not allow such moral violations to become devoid of their horrifying meaning. As humanitarian workers, we maintain humanity when we care, commit, and respond to moral injustices. This refusal to abandon others in desperate situations is an attempt to rectify injustices through witnessing and solidarity. When people are left behind, we must not leave them alone.
\end{abstract}

Ann Fam Med 2020;18:176-178. https://doi.org/10.1370/afm.2521.

$\mathrm{H}$ e was our patient before he even knew what it is to live, his 2-yearold body rigid and hyperextended, contradicting his peaceful baby face. His oxygen mask and makeshift plastic bottle nebulizer could not fully keep him out of respiratory distress likely due to measles's complications. Over the course of 3 to 4 days, his condition waxed and waned, and our hopes mirrored these fluctuations; his mother became near euphoric with minimal improvement and inconsolable with every inevitable decompensation. I explained to her his chances for survival, though the care team's exchanged looks needed no explanation. She had little prior experience with the health care system, but the haunting desperation in her face showed that, as a mother, she viscerally understood.

I, with a young Bengali practitioner, started that morning with medical rounds on about 60 patients in 3 hospital tents-measles isolation, neonatal intensive care and step-down unit, and general medicine/pediatrics. We then moved on to the small emergency department and another isolation tent for suspected diphtheria cases. We rounded again in the afternoon, evening, and early the next morning, while continuously tending to the difficult cases, such as our young patient.

Nights were true nightmares for him. He decompensated almost every 2 hours, and each time we struggled to resuscitate him. My judgements were all made clinically as I did not have ancillary services. His desperate mother inquired about pursuing care from other doctors. The only other field hospital was hours away, had fewer providers and supplies, and transport was too risky. That night she became inconsolable, was taken away by some countrywomen to her other 4 children who had been home alone for days, and the child's father replaced her at bedside.

Around 2:00 AM, I left for an adjacent canteen room, equipped with a cot, mosquito net, table, and flashlight. I had a dinner of biscuits and 
mango juice, spending 45 minutes out of the hospital tents. Although I had instructed the staff to alert me if he became unstable again, I knew they had already given up. The intensity of this case had been prohibiting them from caring for others with better chances for survival. I left his bedside with a sense that the price of my temporary absence could be his life. Not long after, I was told that he had died 10 minutes prior.

I offered his father all I could: an explanation of what had happened and a death certificate. He said he didn't need anything except his son's body. In his eyes, I saw the anguish of a father accepting profound responsibility for a situation out of his control. He took in my words with both devastation and acceptance, absorbing this as yet another atrocity the Rohingyas would face but not allow to break them. I, on the other hand, felt that I had failed him, inadequate and hollow.

As the father wrapped his child in a blanket, I made him one last offering: a flashlight to navigate the camp's darkness, devoid of electricity. He respectfully refused and departed with his lifeless child, swallowed up by the foggy darkness and monotone sound of a far-off speaker playing recited verses of the Quran (Supplemental Figure 1, http://www.annfammed.org/ content/18/2/176/suppl/DC1).

Unfortunately, this family's tragedy was not unique. The needs in the camps were limitless, while our resources were painfully finite. By this measure alone, it was a futile battle. Most situations could not be fixed or even tended to, and many patients could not be healed. However, in the decision to respond and stay, with the knowledge that often there was no available solution, lies the fundamentals of humanity. As humanitarian workers, we must refuse to abandon people through the most desperate circumstances. In this solidarity, we bear witness, maintain our collective conscientiousness, and preserve our humanity. When there is nothing else left, this moral refusal must remain.

For this mission with Medecins Sans Frontieres (MSF), I had arrived at the small and bustling Cox Bazar airport in Bangladesh, and then made a 3-4-hour trip along narrow unpaved roads, foggy and poorly visible, to near the Myanmar border. The air smelled of burning wood, raw vegetables, and rice fields. Political banners abounded, providing an informal situational briefing. My new temporary home was a half-built 2-story building with 7 small rooms, 3 bathrooms, and a communal living room for 24 international staff. Some had to sleep on the roof and balcony under make-shift tents.

The field hospital was made from multiple separate tents and a row of field toilets. Clinical shifts were often 16 hours with 5 days per week in the hospital and additional shifts in clinics. The range of responsibilities was not bound by specialty. I, a general internist, repaired fractures and dislocations, performed minor surgeries, removed foreign objects, treated poisoning and injuries, provided prenatal care, placed contraceptives, responded to psychosocial needs and sexual abuse survivors, and treated infections and chronic diseases; on a larger scale, my organization, MSF, helped respond to epidemics, implement public health measures, and address water and sanitation issues.

The care system in the camp was ill-equipped to provide the constant intensive care so many people required. My colleagues and I offered the highest level of care we could while faced with inadequate systems: few trained staff (a couple of nurses and nurse aids and some local generalists with no intensive care unit [ICU] experience), no blood gas monitoring, no ventilators, no radiology, and very limited laboratories. The challenge before us - vast camps ravaged by diphtheria and measles outbreaks superimposed on myriad other maladies - was disproportionate to our resources.

To address the outbreaks, the obvious answer was to vaccinate within a few weeks of the refugees' arrival. The Government of Bangladesh, however, was reticent to declare diphtheria or measles outbreaks, largely to avoid risking a well-deserved international reputation of remarkable vaccination and primary care coverage; when the outbreaks were formally recognized, the measles outbreak had already declined. Measles was like the rainy season: overwhelming initial intensity and then rapidly dying out. Diphtheria, however, had a more prolonged course with high mortality.

Diphtheria was a difficult clinical diagnosis, but my colleagues and I rapidly developed a protocol for diagnosis, treatment, and community response. Our clinical prediction rule featured documented fever, distinctive gray pharyngeal exudate, adenopathy, lack of upper respiratory tract infection symptoms, and probable exposure based on location. We gave first doses of azithromycin, started contact tracing and prophylactic antibiotics, and transferred the patient to an adjacent center that my organization, MSF, dedicated solely to diphtheria with inpatient antibiotics and anti-toxin. The World Health Organization had already declared the epidemic with laboratory diagnoses of initial cases.

My MSF hospital, however, was primarily designated for measles. It was challenging to distinguish this rash from many others, but my colleagues and I also applied a clinical case definition during the epidemic. The measles cases progressed rapidly, exacerbated by the associated pneumonia, conjunctivitis, diarrhea, stomatitis, other superimposed infections, and malnutrition. Even before vaccination, the caseload dropped by $80 \%$ within 6 to 8 weeks. Despite these limitations, 
MSF erected a tent-based hospital with sanitation, electrical and water supplies in about 3 weeks for a population of around 200,000. My colleagues and I quickly introduced practical training and practicebased learning, adjusted to the pathologies before us, and maintained a weekly mortality of 1 to 2 deaths among patients seen in the camp's clinics and hospital (Supplemental Figure 2, http://www.annfammed.org/ content/18/2/176/suppl/DC1).

After decades of humanitarian work, again and again I have realized the profound limitations of what humanitarian workers can provide. I have come to understand that need is endless, that resources are finite, and that death is inevitable. These confines inevitably force the allocation of resources through unimaginable choices. This does not mean, however, that those forced to make these decisions condone the choices or their outcomes. While the shortcomings of humanitarian interventions are abundant, these inadequacies should not define or invalidate the meaning of these efforts. The purpose of humanitarian action is not to solve the conflict or bring about justice but to alleviate suffering, as a citizen response to political failure. Amid such atrocities, we maintain our human- ity when we care, commit, and stand by each other in unimaginable times.

This physical solidarity and witnessing unite us, distinct as a species, in our vivid, visceral, and profound response to moral injustice. This is how we can attempt to rectify the most unjust situations. When people are left behind, we offer them our presence and refuse to leave them alone. When it is endlessly dark, we must exercise solidarity, even if only with a flashlight.

To read or post commentaries in response to this article, see it online at http://www.AnnFamMed.org/content/18/2/176/.

Submitted June 10, 2019; submitted, revised, October 14, 2019; accepted November 4, 2019.

Key words: humanitarian; ethics; diphtheria; measles; Rohingya; refugees; humanity

Acknowledgments: The author immensely thanks Ms Elena Beideck, medical student, for her eloquent edits of this paper. Views and opinions expressed in this paper are solely those of the author.

Supplemental materials: Available at http://www.AnnFamMed. org/content/18/2/176/suppl/DC1/.

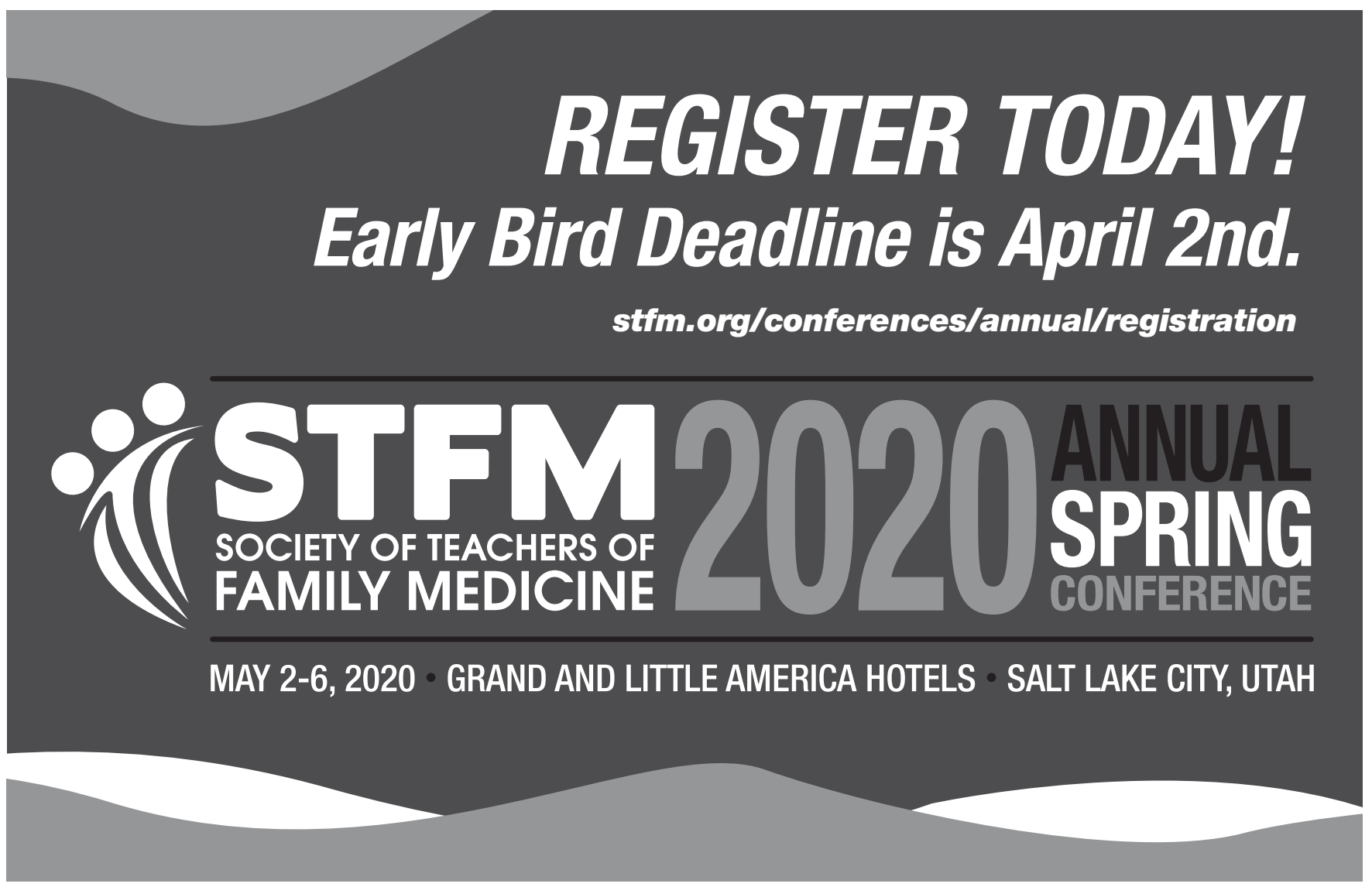

